\title{
PENGEMBANGAN BUKU AJAR STATISTIK SEBAGAI PENUNJANG PERKULIAHAN
}

\author{
Nusrotus Sa'idah \\ FTIK UNISNU Jepara \\ Nusrotussaidah17@gmail.com
}

\begin{abstract}
Abstrak
This research is a development that aims to develop teaching materials that meet the criteria and quality. The teaching materials as supporting lectures statistics in order to improve learning in the classroom so that students have an understanding and skills in statistical skills independently. Textbook development procedure consists of four phases: planning, organizing, implementation and evaluation. Textbook material in accordance with the lesson plans the statistics shown by the example and the same practice with SPSS. Results of the assessment of the reviewer obtained both categories with an average score of 38.41 as seen from all aspects, namely, the aspect of the writing approach, the concept of truth, the depth and breadth of the concept, clarity sentence, linguistic, evaluation, feasibility, structure handouts, physical penampila book instructional and reference library. This textbook memeiliki high criteria in truth the concept and structure of the handout. The development of this textbook in accordance with the syllabus, suitability tests (sample) describing the material, the components of a complete book compiled. Practicability test is done so that the student can pass judgment textbooks with material tailored to ability. Practicability test results by the students gain an average score of 92.5 which indicates very good or practical to use as a reference source in the course of independent learning statistics.
\end{abstract}

Key word : teaching material development, statistics

\begin{abstract}
ABSTRAK
Penelitian ini merupakan penelitian pengembangan yang bertujuan untuk mengembangkan bahan ajar yang memenuhi kriteria dan kualitas. Bahan ajar ini sebagai penunjang perkuliahan statistika guna meningkatkan pembelajaran dalam kelas sehingga mahasiswa memiliki pemahaman dan skill ketrampilan dalam statistik secara mandiri. Prosedur pengembangan buku ajar ini terdiri atas 4 tahap yaitu : perencanan, pengorganisasian, pelaksanaan dan evaluasi. Materi buku ajar sesuai dengan rencana pembelajaran statistik yang ditampilkan dengan contoh dan apliksi dengan spss. Hasil dari penilaian reviewer diperoleh kategori baik dengan skor rata-rata 38,41 yang dilihat dari keseluruhan aspek yaitu, yakni aspek pendekatan penulisan, kebenaran konsep, kedalaman dan keluasan konsep, kejelasan kalimat, kebahasaan, evaluasi, keterlaksanaan, struktur handout, penampila fisik buku ajar dan pustaka acuan. Buku ajar ini memeiliki kriteria tinggi pada kebenaran konsep dan struktur handout. Hal ini di jelaskan pada hasil uji kepraktisan oleh mahasiswa mendapatkan skor rata-rata 92,5 yang menunjukkan sangat baik atau praktis digunakan sebagai acuan sumber belajar pada perkuliahan statistik.
\end{abstract}

Kata kunci : pengembangan buku ajar, statistik 


\section{PENDAHULUAN}

Pendidikan Matematika di Indonesia saat ini sedang mengalami perubahan paradigma, statistik adalah salah satu rumpun dari matematika. Statistik lebih bermakna bagi peserta didik dan dapat memberikan bekal kompetensi yang memadai baik untuk baik studi lanjut maupun untuk memasuki dunia kerja. Umumnya lapangan kerja saat ini lebih menuntut kemampuan menganalisis daripada melakukan pekerjaan yang bersifat prosedural ataupun mekanistis sehingga pada era sekarang ini mahasiswa memerlukan lebih banyak matematika untuk menjawab tantangan hidup dalam arena persaingan global. Selain itu statistik juga dapat digunakan untuk mengasah pola pikir seseorang agar dapat mengapilkasikan ketrampilan yang dimilikinya untuk menyelesaikan permasalahan dalam kehidupannya.

Peningkatan mutu pendidikan diantaranya adalah media pembelajaran yang dibutuhkan dalam proses pembelajaran. Dimana proses belajar mengajar hakekatnya adalah terjadinya interaksi antara guru dengan peserta didik. Salah satu yang cara untuk meningkatkan prestasi belajar mahasiswa dengan menekankan pada pemahaman mahasiswa dalam materi tersebut. Adanya pengembangan buku ajar diharapkan dapat meningkatkan pemahaman siswa pada mata kuliah statistik. Terdapat banyak jenis bahan ajar yang ada seperti buku, modul, dan diktat. Pembelajaran akan berjalan secara efektif dan efisien jika menggunakan bahan ajar yang sesuai dengan kebutuhan mahasiswa, mendukung kompetensi yang hendak dicapai mahasiswa, memiliki uraian yang sistematis, tes yang terstandar serta strategi pembelajaran yang sesuai bagi mahasiswa. Oleh karena itu, seorang dosen harus mampu menyiapkan bahan ajar dan juga strategi pembelajaran yang cocok dalam setiap pembelajaran di kelas.

Selama proses pembelajaran ini bahan ajar yang digunakan adalah handout dibuat seadanya, tanpa memandang kebutuhan dan kemampuan mahasiswa itu sendiri. Mahasiswa yang merasa bosan mengikuti pembelajaran dan sulit memahami materi pelajaran maka akan menyita waktu yang lama. Hal ini mengakibatkan proses pembelajaran menjadi tidak efisien dari segi waktu dan pembelajaran menjadi tidak efektif selain itu mahasiswa tidak dapat belajar mandiri. Karena materi yang terdapat dalam buku paket terdapat pemahaman bahasa yang berbeda untuk mahasiswa. Bahan ajar dari handout hanya memaparkan pokok materi saja tanpa adanya latihan sebagai pembelajaran mandiri.

Dalam penelitian ini bertujuan mendiskripsikan hasil pembuatan produk bahan ajar statistika meliputi desain buku ajar, contoh yang disajikan setelah sub pokok bahasan, evaluasi mandiri dan aplikasi materi dengan spss, mengetahui karakteristik dan kualiatas buku ajar statistik, dan Mengetahui kepraktisan dan efektifitas buku ajar dalam pembelajaran mata kuliah statistik.

Tahap selanjutnya sebagai peneliti mengharapkan adanya partisipasi untuk mengembangkan pengbdian masyarakat dalam pendampingan pelatihan pembuatan buku ajar atau modul yang baik dalam proses perkuliahan sehingga mahasiswa dapat belajar mandiri.

\section{Tinjauan Pustaka}

\section{Pembelajaran Statistik}

Belajar bukan menghafal bukan pula mengingat. Belajar adalah suatu proses yang ditandai dengan adanya perubahan pada diri seseorang. Perubahan sebagai hasil proses belajar dapat ditunjukkan dalam berbagai bentuk seperti perubahan pengetahuannya, pemahamannya, sikap dan tingkah lakunya, ketrampilannya, kecakapan dan kemampuannya, daya reaksinya dan daya penerimaanya dan aspek lain yang ada pada individu (Sudjana, 2005:28). Pada proses pembelajaran sebenarnya memilih, menetapkan

\section{Jurnal Refleksi Edukatika}

Vol. 6 No. 2 Juni 2016 
dan mengembangkan media belajar untuk mencapai keberhasilan dalam pembelajaran.

Penggunaan statistika sudah dikenal sebelum abad 18, pada saat itu negara babilon, roma mengeluarkan catatan tentang nama, usia , jenis kelamin, pekerjaan dan jumlah anggota keluarga. Di indonesia pengantar statistik sudah dicantumkan dalam kurikulum matematika Sekolah Dasar sejak tahun 1975. Hal ini disebabkan karena sekitar lingkungan kita berada selalu berkaitan dengan satistik. Misalnya di kelurahan sudah mengenal adanya statistik desa, yang memuat kedaan penduduk mulai dari banyak penduduk, banyak anak dan sebagainya.

Statistik Menurut Lyman and Michael Longnecker (2010:2) menyatakan bahwa:

Statistics is the science of designing studies or experiments, collecting data and modeling/analyzing data for the purpose of decision making and scientific discovery when the available information is both limited and variable. That is, statistics isthe science of Learning from Data.

Statistika merupakan cabang ilmu yang mempelajari tentang bagaimana merencanakan, mengumpulkan, menganalisis, menginterpretasi dan mempresentasikan data serta menarik kesimpulan berdasarkan kumpulan data dan penganalisisan yang dilakukan. Kumpulan data yang telah diolah akan dapat menghasilkan suatu analisis data yang akurat. Pada umumnya pembelajaran statistik dalam perkuliahan hanya menyimak handout saja dari dosen yang menyebabkan mahasiswa menjadi bosan. Untuk meningkatkan motivasi belajar statistik dengan adanya buku ajar ini sebagai pegangan untuk belajar mandiri.

Ruang lingkup statistik meliputi statistik deskriptif dan statistik inferensial. Statistik deskriptif meliputi menghimpun data, menyusun data, mengolah data, menyajikan data dan menganalisis data angka sedangkan statistik inferensial meliputi probabilitas, penaksiran dan pengujian hipotesis, korelasi dan komparasi (Hartono,2008 : 3 ). Statistik memegang peranan penting dalam penelitian, baik dalam penyusunan model, perumusan hipotesa, dalam pengembangan alat dan instrumen pengumpulan data, penyusunan desain penelitian, penentuan sampel dan analisis data. Statistik dapat digunakan sebagai alat ukur untuk mengetahui kausalitas penelitian.

Menurut Lyman dan Michael Longnecker (2010 : 6) alasan adanya pembelajaran statistik yaitu :

1. you need to know how to evaluate published numerical facts

2. studying statistics is that your profession or employment may require you to interpret the results of sampling (surveys or experimentation) or to employ statistical methods of analysis to make inferences in your work

menurut pendapat diatas dapat disimpulkan bahwa kita belajar statistik untuk mengetahui bagaimana mengevaluasi data numeric dan menginterpretasikan dari analisi data.

Dosen memiliki peran yang sangat penting dalam menentukan kuantitas dan kualitas pengajaran yang dilaksanakannya. Oleh sebab itu, dosen harus memikirkan dan membuat perencanaan secara seksama dalam meningkatkan kesempatan belajar bagi mahasiswanya dan memperbaiki kualitas mengajarnya khususnya pembelajaran statistik. Pembelajaran statistik memegang peranan penting dalam penelitian yang digunakan dalam analisis data. Pemahaman dalam statistik harus ditekankan oleh dosen terhadap mahasiswa karena sebagai bekal untuk penelitian dalam analisis data.

Pengembangan buku ajar harus disesuaikan dengan kurikulum. Standar kompetensi dan kompetensi dasar sebagai acuan untuk membuat buku ajar. Kedalaman materi dengan urutan materi yang sesuai serta perlakuan terhadap materi menjadi penting dalam pembutan buku ajar. Materi Statistik 
dalam perkuliahan prodi PAI adalah sebagai berikut

Tabel 1. Materi Statistik

\begin{tabular}{|c|c|c|}
\hline $\begin{array}{l}\text { Tatap } \\
\text { muka }\end{array}$ & $\begin{array}{c}\begin{array}{c}\text { Kemampuan akhir yang } \\
\text { diharapkan }\end{array} \\
\end{array}$ & Materi Bahan Ajar \\
\hline 1 & \multirow{2}{*}{$\begin{array}{l}\text { Memiliki pemahaman statistik, } \\
\text { data statistik dan alat penyaji data } \\
\text { statistik serta trampil dalam } \\
\text { menyajikan data }\end{array}$} & $\begin{array}{l}\text { Pendahuluan dan Data Statistik } \\
\text { - Ruang lingkup statistik (pengertian dan } \\
\text { jenis statistik) }\end{array}$ \\
\hline 2 & & $\begin{array}{l}\text { - Peranan dan tujuan statistik } \\
\text { - jenis data statistik }\end{array}$ \\
\hline 3 & \multirow{3}{*}{$\begin{array}{l}\text { Mahasiswa memahami Distribusi } \\
\text { Frekuensi serta dapat } \\
\text { mengaplikasikan }\end{array}$} & - Penyajian data : tabel, grafik, diagram \\
\hline 4 & & - Perhitungan Frekuensi komulatif dan relatif \\
\hline 5 & & Grafik dan diagram Distribusi frekuensi \\
\hline 6 & \multirow{7}{*}{$\begin{array}{l}\text { Memiliki pemahaman dan } \\
\text { ketrampilan dalam menganalisis } \\
\text { statistik deskriptif }\end{array}$} & Ruang lingkup Tendensi sentral \\
\hline 7 & & Mean \\
\hline 8 & & Median,Modus \\
\hline 9,10 & & Ukuran despersi (Kuartil, desil, persentil \\
\hline 11 & & Range, mean deviation \\
\hline 12,13 & & Varian si, Simpangan baku (standar deviasi) \\
\hline \multirow[t]{2}{*}{14} & & Angka baku (kofesien variansi) \\
\hline & Statistik Lanjutan & \\
\hline \multirow[t]{5}{*}{15} & \multirow{5}{*}{$\begin{array}{l}\text { Mahasiswa mampu memahami dan } \\
\text { mengaplikasian dengan latihan } \\
\text { sederhana analisis data statistik } \\
\text { inferensial }\end{array}$} & Analisis korelasi \\
\hline & & Analisis Regresi \\
\hline & & Uji homogenitas \\
\hline & & Analisis komparasi \\
\hline & & One way Anova dan Two Way anova \\
\hline
\end{tabular}

\section{Pengembangan Buku Ajar}

Buku ajar bersifat sistematis artinya disusun secara urut sehingga memudahkan untuk belajar. Di samping itu buku ajar juga bersifat unik dan spesifik. Unik maksudnya buku ajar hanya digunakan untuk sasaran tertentu dan dalam proses pembelajaran tertentu, dan spesifik artinya isi buku ajar dirancang sedemikian rupa hanya untuk mencapai kompetensi tertentu dari sasaran tertentu. Dalam kegiatan proses perkuliahan buku ajar berperan penting bagi mahasiswa dan dosen. Dosen akan mengalami kesulitan untuk meningkatkan efektifitas perkuliahan tanpa adanya buku ajar karena mata kuliah ini dinilai sangat sulit untuk menangkap pemahaman materi. Hal ini akan menimbulkan dampak bagi mahasiswa juga apabila dalam menjelaskan sangat cepat dan kurang jelas. Oleh karena itu pengembangan buku ajar sebagai salah satu alternatif untuk meningkatkan kualitas perkuliahan.

Pengembangan buku ajar ini merupakan budaya buku yang menjadi salah satu tanda masyarakat yang maju. Buku ajar ini sebagai wujud layanan untuk memfasilitasi mahasiswa. Dengan ini mahasiswa dapat mengoptimalkan kemampuan untuk mempelajari statistik secara berulang-ulang.

Untuk memenuhi buku ajar yang layak digunakan dalam proses pembelajaran harus sesuai dengan karakteristik buku ajar yaitu :

\section{Jurnal Refleksi Edukatika}


a. Sesuai dengan kebutuhan belajar dan karakteristik pendidik.

b. Kesesuaian dengan kurikulum

c. Kesesuaian pengembangan materi dengan tema/topik

d. Penggunaan/pemakaian bahasa

e. Bermakna bagi peningkatan kompetensi pendidik dan mudah dipahami

f. Memiliki nilai guna sehingga dirasakan benar manfaatnya oleh mahasiswa dan dosen.

Menurut Sugiyono (2010:407) menyatakan bahwa pengembangan ini merupakan penelitian yang menghasilkan produk tertentu, dan menguji kefektifan produk tersebut. Untuk menghasilkan produk tertentu digunakan penelitian yang bersifat analisis kebutuhan dan menguji kefektifan produk tersebut agar berfungsi di masyarakat luas.

Menurut Borg \& Gall penelitian pengembangan adalah suatu proses yang dipakai untuk mengembangkan dan memvalidasi produk pendidikan. Penelitian ini mengikuti suatu langkah-langkah secara siklus. Langkah-langkah penelitian atau proses pengembangan ini terdiri atas kajian tentang temuan penelitian produk yang akan dikembangkan, pengembangan produk berdasarkan temuan-temuan tersebut, melakukan uji coba lapangan sesuai dengan latar dimana produk tersebut akan dipakai, dan melakukan revisi terhadap hasil uji lapangan.

Menurut Borg \& Gall (1983:772) menyatakan bahwa:

"Educational research and development $(R \& D)$ is a process used to develop and validate educational product. The steps of this process are usually referred to as the $R \& D$ cycle, which consist of sudying research findings partinent to the product $t$ be developed, developing the product based on the finding, field testing it the setting where it will be used eventually and revising it to correct the deficiencies found in the field testing stage. In indicate that product meets behaviorally defined objectives.

Dari penjelasan Borg \& Gall dapat disimpulkan bahwa riset dan pengembagan bidang pendidikan $(\mathrm{R} \& \mathrm{D})$ adalah proses untuk mengembangkandan mengesahkan produk dalam pendidikan. Langkah-langkah dalam riset pengembangan melalui tahapan dari pengkajian, pengujian, peninjauan ulang, mengoreksi produk sehingga temuan ini dilakukan mempunyai objektivitas.

\section{Metode Penelitian}

Jenis penelitian ini adalah penelitian pengembangan atau Research and Development (R \& D). Menurut Sugiyono (2011 : 298), penelitian dan pengembangan juga didefinisikan sebagai suatu metode penelitian yang digunakan untuk menghasilkan produk tertentu dan menguji keefektifan produk tersebut.

Dalam penelitian ini objek penelitian sebagai sampel yaitu pertama buku ajar yang memuat materi statistik meliputi kompetensi tau kemampuan akhir dari pembelajaran, content atau materi pokok bahasan statistika, latihanlatihan soal. Yang kedua dilakukan di FTIK UNISNU Jepara yaitu mahasiswa PBI semester 5 yang menempuh mata kuliah statistika. Pengambilan sampel dengan cara purposive sampling.

Prosedur penelitian R\&D memiliki sepuluh langkah, yaitu: potensi dan masalah, pengumpulan data, desain produk, validasi desain, revisi desain, uji coba produk, revisi produk, uji coba pemakaian, revisi produk, dan produksi masal. Pada penelitian ini tidak semua langkah dapat dilakukan oleh peneliti karena keterbatasan tenaga dan waktu. Prosedur penelitian pengembangan ini digambarkan, seperti pada gambar 1 . 


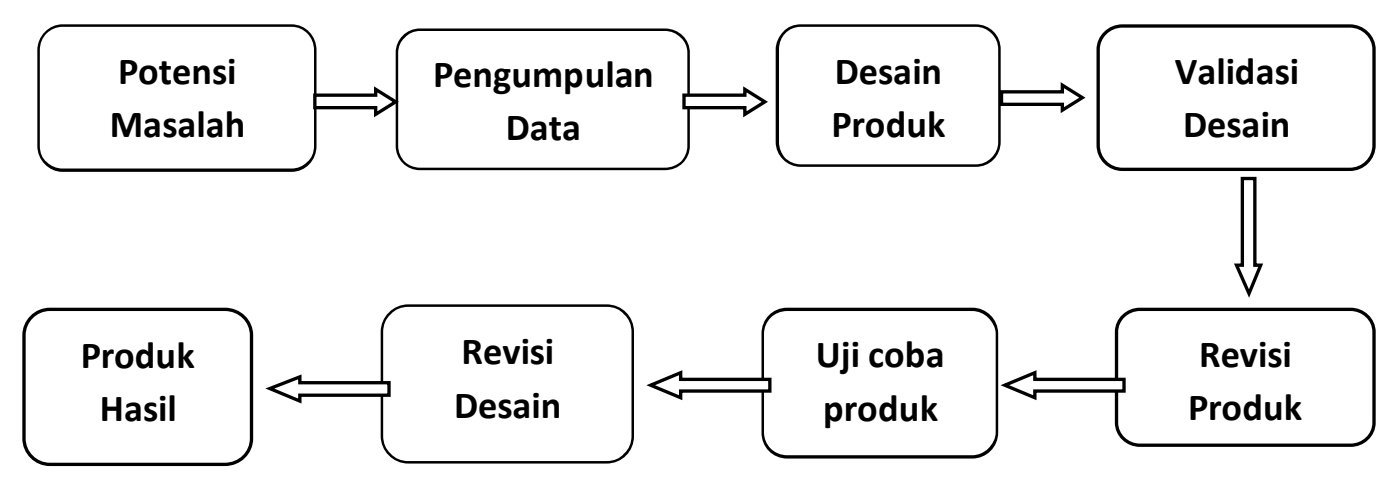

Gambar 1. Rancangan Pengembangan Buku Ajar

Secara umum instrumen yang digunakan dalam penelitian ini adalah lembar validasi tenaga ahli yang diisi oleh 1 orang dosen lain yang mempunyai keahlian di bidang statistika. Kedua, lembar tanggapan mahasiswa berupa angket. Pada lembar kepraktisan memuat pernyataan yang berhubungan dengan praktikalitas buku ajar statistik untuk mahasiswa PBI UNISNU jepara. Lembar validasi tenaga ahli disusun berdasarkan indikator yang telah ditentukan, yaitu 1) pendekatan penulisan, 2)kebenaran konsep , 3) kedalaman dan keluasan konsep, 4) kejelasan konsep, 5) kebahasaan, 6) evaluasi, 7 ) keterlaksanaan, 8) Struktur buku, 9) Penampilan fisik Buku Ajar, 10) Pustaka Acuan Indikator tersebut dijabarkan menjadi beberapa pertanyaan.

Instrumen selanjutnya adalah lembar kepraktisan yang dutujukan pada dosen yang serumpun atau sesuai keahliannya dan mahasiswa. Lembar uji kepraktisan terdiri dari dua jenis, yaitu: Pertama, lembar uji kepraktisan menurut dosen terkait ilmu statistik yang terdiri dari beberapa indikator antara lain: Indikator-indikator tersebut meliputi:

1. Buku ajar memiliki tampilan yang menarik

2. Komposisi tulisan dan warna yang digunakan pada buku menarik
3. Gambar dan tulisan dalam buku ajar menarik

4. Saya menjadi senang dan termotivasi mempelajari statistik dengan menggunakan buku ajar bermuatan drill atau latihan soal

5. Pembelajaran statistik dengan menggunakan buku ajar bermuatan drill atu latihan dari materi pelajaran yang dapat diterapkan dalam kehidupan sehari-hari

6. Buku ajar dilengkapi dengan soal berupa lembar kerja yang dapat meningkatkan kerja keras, kreatif dan berfikir kritis

7. Buku ajar ini dapat meningkatkan pemahaman saya terhadap materi statistik yang sedang saya pelajari

8. Gambar membantu saya dalam memahami materi statistik yang sedang saya pelajari

9. Pembelajaran statistik dengan menggunakan buku ajar ini membuat saya cepat memahami materi yang digunakan dalam penelitian

10. Penyajian materi dalam buku ajar lebih praktis dan dapat dipelajari berulangulang

11. Saya dapat belajar mandiri dengan menggunakan buku ajar ini 
12. Pembelajaran menggunakan buku ajar ini dapat menjalin kerja sama sesama kelompok

13. Tampilan SPSS dalam buku ajar ini memahamkan saya dalam mempelajari statistik

Analisis data menggunakan perhitungan kualitas dengan kriteria sangat baik, baik, cukup, kurang dan sangat kurang. Data penilaian yang sudah diubah menjadi nilai kuantitatif dan dirata-rata seperti terlihat pada" Tabel Data Skor" diubah menjadi nilai kualitatif sesuai dengan kriteria kategori penilaian dengan ketentuan sebagai berikut :

\begin{tabular}{|c|l|l|}
\hline No & \multicolumn{1}{|c|}{ Rentang Skor } & \multicolumn{1}{|c|}{ Kategori Kualitatif } \\
\hline 1 & $\bar{X}>\left(\mathrm{M}_{\mathrm{i}}+1,5 \mathrm{SB}_{\mathrm{i}}\right)$ & Sangat baik \\
\hline 2 & $\left(\mathrm{M}_{\mathrm{i}}+0,5 \mathrm{SB}_{\mathrm{i}}\right)<\bar{X} \leq\left(\mathrm{M}_{\mathrm{i}}+1,5 \mathrm{SB}_{\mathrm{i}}\right)$ & Baik \\
\hline 3 & $\left(\mathrm{M}_{\mathrm{i}}-0,5 \mathrm{SB}_{\mathrm{i}}\right)<\bar{X} \leq\left(\mathrm{M}_{\mathrm{i}}+0,5 \mathrm{SB}_{\mathrm{i}}\right)$ & Cukup \\
\hline 4 & $\left(\mathrm{M}_{\mathrm{i}}-1,5 \mathrm{SB}_{\mathrm{i}}\right)<\bar{X} \leq\left(\mathrm{M}_{\mathrm{i}}-0,5 \mathrm{SB}_{\mathrm{i}}\right)$ & Kurang \\
\hline 5 & $\bar{X} \leq\left(\mathrm{M}_{\mathrm{i}}-1,5 \mathrm{SB}_{\mathrm{i}}\right)$ & Sangat kurang \\
\hline
\end{tabular}

Untuk uji kepraktisan di analisis dengan hasil rata-rata responden dari setiap aspek yang dianalisis dengan microsoft excell.

\section{HASIL PENELITIAN PEMBAHASAN}

\section{HASIL PENELITIAN}

Analisis data berupa uji validasi atau penilaian dari reviewer dan uji kepraktisan oleh mahasiswa yang mengikuti mata kuliah statistik. Hasil penilaian dari reviewer menghasilkan penilaian dengan kriteria baik yang dilihat dari keseluruhan aspek. Untuk hasil penilaian reviewer oleh dosen yang sesuai dengan kualifikasi yaitu bidang ahli statistik dan penelitian dari Universitas Mulawarman. Hasil uji menunjukkan kriteria baik dengan skor rata-rata 38,41 yang dilihat dari keseluruhan aspek. Hasil perhitungan dapat dilihat pada lampiran. Nilai rata -rata tiap aspek tertinggi pada aspek Kebenaran konsep dan struktur Handout yaitu dengan skor rata-rata 4,33. Nilai dari reviewer dapat digambarkan dengan diagram batang sebagai berikut.

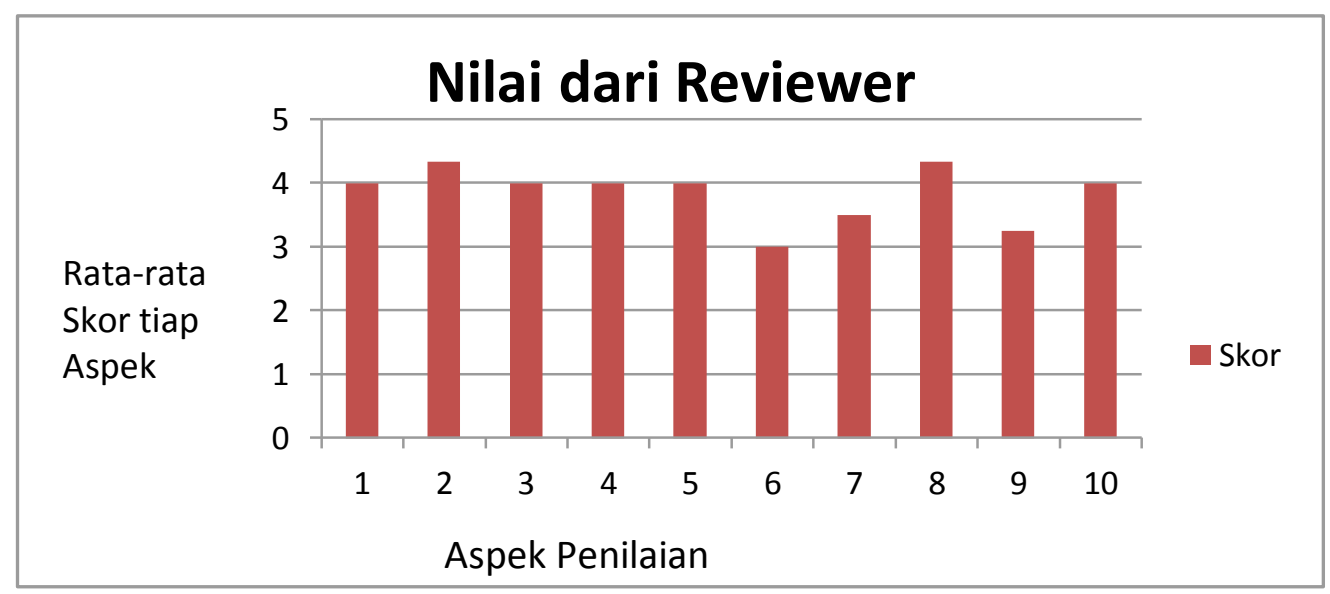

Gambar 3. Nilai dari Reviewer 
Hasil Uji kepraktisan oleh mahasiswa dengan perhitungan uji kepraktisan dilihat dari kriteria penilaian dari 1 sampai dengan 5, jumlah mahasiswa yang memberikan tanggapan handout adalah sebanyak 25 mahasiswa untuk mengambil data agar representatif. Skor terendah untuk setiap pernyataan adalah 1 dan skor tertinggi adalah 5. Skor setiap pernyataan yang diperoleh dikonversi ke dalam bentuk nilai sehingga nilai terendah 25 dan nilai tertinggi 125. Data nilai di sajikan dalam diagram batang berikut.

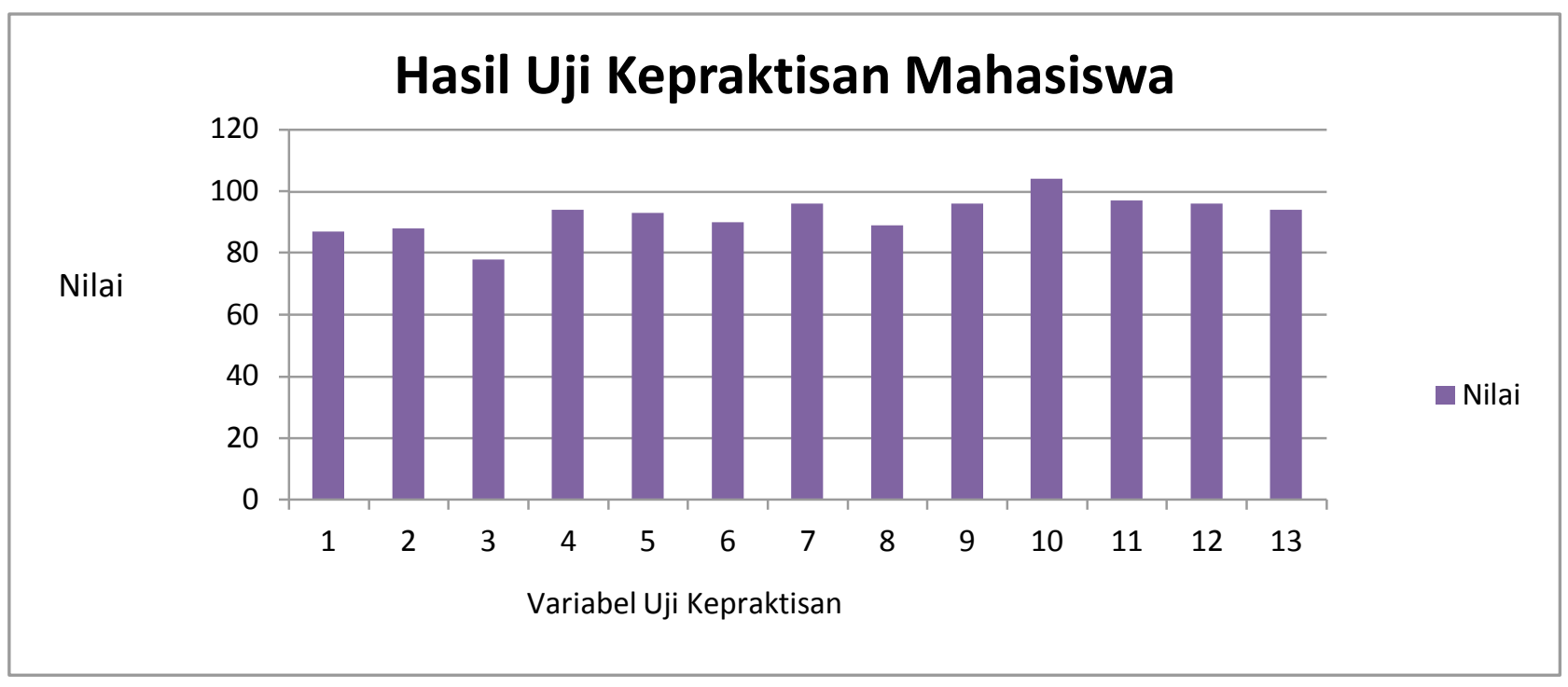

Gambar 4. Grafik Nilai Variabel Uji Kepraktisan Mahasiswa

\section{PEMBAHASAN}

Berdasarkan hasil validasi buku ajar yang dinilai oleh dosen dengan kualifikasi bidang statistik dan penelitian yakni 10 aspek penilaian yakni aspek pendekatan penulisan, kebenaran konsep, kedalaman dan keluasan konsep, kejelasan kalimat, kebahasaan, evaluasi, keterlaksanaan, struktur handout, penampila fisik buku ajar dan pustaka acuan. Buku ajar sebagai acuan perkuliahan yang dikembangkan memenuhi kriteria penilaian baik. Nilai tertinggi yaitu pada aspek Kebenaran konsep dan struktur Handout hal ini menunjukkan bahwa isi dari buku ajar statistik tersebut sudah sesuai dengan materi pada silabus mata kuliah statsitik. Kebenaran konsep ini mambantu mahasiswa mencapai kompetensi pada silabus, kesesuaian contoh disela-sela uraian dan kejelasan tugas. Untuk struktur handout ketepatan judul dengan materi tersusun dengan urut sesuai dengan bab yang sistematis.
Buku ajar statistik sangat praktis dan efektif digunakan dalam perkulihan statistik, hal ini dikarenakan buku ajar yang dikembangkan dapat meningkatkan kompetensi siswa baik dari segi kognitif, afektif maupun psikomotor. Segi kognitif mahasiswa dilihat dari hasil nilai yang baik dari latihan dari umpan balik dalam buku ajar. Pada ranah afektif nilai-nilai karakter yang diamati antara lain: berfikir kritis, kreatif, kerja sama dan kerja keras. Untuk aspek psikomotor, mahasiswa melakukan eksperimen menggunakan buku ajar yang telah dilengkapi dengan lembar kerja. Lembar kerja ini dapat menuntun siswa untuk bekerja sama dengan anggota kelompoknya. Mahasiswa dapat belajar mandiri dengan menggunakan buku ini seperti latihan analisis data dengan excell maupun spss.

Dalam pembuatan buku ajar ini masih terdapat keterbatasan dan kendala. Keterbatasan pada penulisan ini adalah materi yang dikembangkan dari materi tersebut masih

\section{Jurnal Refleksi Edukatika}

Vol. 6 No. 2 Juni 2016 
terbatas. Sedangkan kendala yang dihadapi adalah kesulitan dalam melakukan penilaian reviewer yang sesuai dengan bidang keahlian dan uji kepraktisan. Reviewer pada penulisan buku ini hanya 1 orang untuk 25 orang mahasiswa sebagai responden uji kepraktisan buku. Berdasarkan kendala dan keterbatasan yang ada dapat dikemukakan beberapa solusi yaitu untuk kedepannya lebih dipersiapkan penyajian materi secara mendalam dan latihan soal sebagai umpan balik dan menggali mahasiswa dalam perkuliahan secara mandiri.

\section{KESIMPULAN}

Berdasarkan analisis desain produk dan data dapat dikemukakan dalam pengembangan buku ajar statistik untuk perkuliahan dapat disimpulkan yaitu: buku ajar memiliki validitas penilaian dengan kategori baik dari keseluruhan aspek, dan buku ajar statistik memiliki penilaian sangat praktis oleh mahasiswa sebagai acuan pembelajaran mandiri.

\section{DAFTAR PUSTAKA}

Borg \& Gall. 2003. Educational Research. USA: Alyn and Bacon
Depdiknas. 2005. Peraturan Mentri Pendidikan Nasional No.11 tahun 2005. Jakarta : Direktorat Pendidikan Dasar dan Menengah.

Hadi, Sutrisno. 2015. Metodologi Riset. Yogyakarta: Pustaka Belajar

Sudaryono. 2014. Teori dan Aplikasi dalam Statistik. Yogyakarta: Andi Offset

Hartono. 2009. Statistik untuk Penelitian. Yogyakarta : Pustaka Pelajar

Lyman Ott and Michael Longnecker. 2010. An Introduction to statistics with data analysis. Belmont

Brooks/Cole,Cengage Learning

Sudjana, Nana. 2005. Dasar dasar proses Belajar Mengajar. Bandung : Sinar Baru Algensindo

Sudijono, Anas. 2012. Pengantar Statistik Pendidikan. Jakarta : Grafindo Persada

Sugiyono. 2010. Metode Penelitian pendidikan. Bandung : Alfabeta 